\title{
KA'Á WATÁ, “ANDAR NA FLORESTA”: CAÇA E TERRITÓRIO EM UM GRUPO TUPI DA Amazônia
}

\author{
Uirá Garcia ${ }^{1}$
}

\begin{abstract}
Resumo
Com base na análise das formas pelas quais o território é concebido e utilizado durante as caçadas em um povo tupi-guarani da Amazônia oriental, os Awá-Guajá, o presente artigo propõe uma primeira análise sobre a concepção de território e mobilidade territorial neste povo. Apresento as noções de harakwá e watá, argumentando que as ações envolvidas na floresta, expressas sobretudo pelas ideias de "andar" e "caçar", são centrais para o entendimento da territorialidade awá-guajá.
\end{abstract}

Palavras-Chave: Território. Caça. Awá-Guajá. Harakwá. Watá.

\section{KA'Á WATÁ, “TO WALK IN THE FOREST": HUNTING AND TERRITORY IN AN AMAZONIAN TUPI GROUP Abstract}

Based on the analysis of how territory is conceived and used during hunting activities by a Tupi-Guarani community from eastern Amazon, the Awá-Guajá, this article proposes an initial analysis of the conception of territory and territorial mobility for this community. I present the notions of harakwá and watá, arguing that the actions

\footnotetext{
${ }^{1}$ Pós-doutorando no Departamento de Antropologia da Unicamp; Pesquisador do Centro de Estudos Ameríndios da USP (CESTA-USP) e do Centro de Pesquisa em Etnologia Indígena da Unicamp (CPEI-UNICAMP). Bolsista da Fundação de Amparo à Pesquisa do Estado de São Paulo (Fapesp). Brasil. uiragarcia@terra.com.br
} 
in the forest, expressed mainly by the ideas of «to walk» and «to hunt», are central to the understanding of the Awá-Guajá territoriality.

Keywords: Territory. Hunting. Awá-Guajá. Harakwá. Watá.

\section{INTRODUÇÃO}

$\mathrm{D}$ entre as etnografias que abordam a organização espacial de povos amazônicos que encontram na caça uma atividade central, sejam horticultores ou não (ver, por exemplo, o balanço de Rival, 1999), uma das alegorias mais comuns é a do território como um espaço marcado por histórias de caçadas e guerras, uniões matrimoniais e cisões entre afins, nas que os saberes produzidos nas interações com a floresta seriam, todo tempo, colocados à prova e reinventados. São muitos os exemplos: a paisagem supostamente caótica das florestas do Capauari, tão familiares aos Ashuar, um "território varado por mil acontecimentos", que fornecem à paisagem aparentemente anônima sua devida substância histórica (DESCOLA, 2006, p. 153-154); os muitos topônimos existentes no léxico Parakanã para situá-los em suas trilhas, e pelos quais se localizavam durante seus períodos de trekking (FAUSTO, 2001, p. 105); o interesse dos Huaorani em sempre seguir adiante, por seus caminhos, acompanhando o florescimento dos vegetais e o movimento dos animais (RIVAL, 2002, p. 68); o "seminomadismo" Sirionó que, através dos Ñenda, os caminhos de caça, descobrem a cada caminhada uma nova floresta, que lhes fornecerá as aldeias-acampamentos em que vivem (HOLMBERG, 1969, p. 105); a cultura material "descartável" dos nômades Yuquí, donde os poucos objetos fabricados (cordas e cestos) são feitos e refeitos de acordo com a necessidade, subprodutos exclusivos de sua bem sucedida relação com a floresta (STEARMAN, 2001, p. 41); as complexas descrições sobre o território realizadas pelos Akuriyó, levando-se em conta, fundamentalmente, a vegetação e a fauna, que coincidem com as descrições presentes "nas melhores enciclopédias de fauna e flora" já produzidas sobre o norte amazônico (JARA, 1996, p. 96). Enfim, em variados contextos etnográficos sul-americanos, entre povos para os quais a caça desempenha um papel fundamental, que enfatiza um permanente estar em movimento na floresta, a produção de múltiplos significados sobre o território é condição primordial à existência da vida. São espaços "culturalizados", nos termos de Ingold, cujas relações são, antes, relações entre pessoas, encarnadas em formas orgânicas, frágeis e impermanentes (INGOLD, 2000, p. 53), e onde a história está escrita no espaço. 
As múltiplas relações entre o ambiente e os seres humanos, como sabemos, são centrais às sócio-cosmologias amazônicas, seja no xamanismo, na guerra ou nas atividades de produção de alimentos; assim, ao nos depararmos com povos nos quais a atividade de caça permeia boa parte da vida social, tal relação aparece como questão central. Neste artigo, apresento as formas pelas quais os Awá-Guajá concebem o "conjunto" caça e território e, em particular, sua forma de articulação. Para tanto, discuto as noções de barakwá2, termo que abrange o domínio territorial e suas relações, e watá, verbo que expressa o processo de "caminhar" e "caçar" na floresta. Busco formular uma interpretação sobre a relação entre caça e território para este povo, na que, suponho, a ideia de um "andar-caçar" desempenha um papel preponderante. Baseado em minha pesquisa de campo de nove meses, este artigo não pretende realizar uma síntese teóricocomparativa, mas sim trazer uma contribuição etnográfica à agenda mais geral da etnologia sul-americana.

\section{Pessoas, caÇa e floresta}

Os Awá-Guajá são um pequeno grupo de caçadores, habitantes da porção oriental da Amazônia, mais exatamente o noroeste do estado do Maranhão, nas bacias dos rios Gurupi, Turiaçú e Mearim. São falantes de uma língua da família Tupi-Guarani e sua população é estimada em 360 pessoas, distribuídas por quatro aldeias em três áreas indígenas diferentes ${ }^{3}$. Nunca possuíram aldeias permanentes e, até o contato, organizavam-se em pequenos grupos, formados por uma ou duas famílias nucleares, dispersos sobre um território também ocupado por outros povos indígenas (Tenetehara e Ka'ápor).

Trata-se de um desses grupos Tupi-Guarani do leste Amazônico, nos que elementos como a fala e o canto, dentre outros, tomam o lugar de uma economia de símbolos e práticas rituais, retomando o que Viveiros de Castro defendeu para os Araweté (VIVEIROS DE CASTRO, 1986, p. 23). Os Awá-Guajá não possuem cerâmica ou cestaria; seu artesanato tradicional se resume a pequenos cocares e braceletes com penas de tucano utilizados em um ritual específico, além de redes de fibras de tucum; as casas, até o contato, eram tapirís na floresta; também não praticavam agricultura até o contato, e os arcos e flechas são os únicos artefatos

\footnotetext{
${ }^{2}$ As Terras Indígenas "Carú", "Awá" e "Alto Turiaçu".

${ }^{3}$ Para a relação entre os Tupi e a agricultura ver, por exemplo, os balanços de Laraia (1986) e Viveiros de Castro (1986).
} 
produzidos em profusão. Os Awá não possuem uma economia hortícola. Milho e mandioca foram introduzidos através da Fundação Nacional do Índio (FUNAI) após o contato com o Estado brasileiro, e nenhum dos subprodutos de uma "agricultura tradicional" indígena — como o fumo, beiju e bebidas fermentadas, tal como encontramos em outros povos amazônicos (e os horticultores Tupi, em particular), poderá ser encontrado aqui. Os espaços de vida, que constituem 0 território Awá, não contemplam a consagrada espacialidade Tupi (e amazônica, de forma geral), que opõem roça e mata como espaços-eventos complementares em um ciclo sazonal. Como um paralelo, mesmo grupos como os Parakanã e os Araweté, que experimentaram, por motivos variados, longos períodos de trekking, com mudanças de aldeias e de população, mantiveram o cultivo de pelo menos um item agrícola - a mandioca, no caso Parakanã, e milho, no caso Araweté (FAUSTO, 2001; VIVEIROS DE CASTRO, 1986). A diferença está no fato dos Awá não possuiriam sequer o milho ou a mandioca.

Desta forma, análises que definem os Tupi como notáveis agricultores, beneficiadores de diversas espécies de mandioca; lavradores aptos ao cultivo das mais variadas culturas: da batata-doce ao fumo, passando pelo cará, milho, amendoim, banana, pimenta, algodão, urucum, jenipapos e até cabaças; produtores de farinhas e beijus; cauins fermentados e doces, dentre outros cultivos específicos, de forma alguma se aplica aos Awá-Guajáa . Historicamente, entre eles só encontramos a caça de animais selvagens, e a coleta dos frutos da floresta ${ }^{5}$. Excetuando a agricultura - que está em uma fase embrionária, sendo introduzida pela FUNAI, e cujos resultados efetivos da incorporação dessa atividade no ciclo de vida dos Awá só poderão ser percebidos de forma satisfatória dentro de algumas décadas, a caça é a principal atividade praticada pelos Awá, e todas as outras (pesca, coleta de mel e frutos) tributárias dela ou postas em segundo plano. Todas as atividades encontram a caça: extrair mel, coletar frutos (pequis, cupuaçu, bacuri, bacaba, inajá, dentre outros) e até mesmo "trabalhar" nas roças com a FUNAI, estão sujeitas a serem abandonadas ou transformadas em caçada

\footnotetext{
${ }^{4}$ Sobre a hipótese da regressão agrícola enfatizada por Balée, que prescreve a perda da agricultura entre os Awá-Guajá, ver: Balée (1994); Cormier (2003); Forline (1997); Garcia (2011).

${ }^{5}$ Os funcionários do posto se referem ao território demarcado por "área", como é de praxe no jargão da FUNAI, e, de forma muito perspicaz, os Awá entenderam que a melhor tradução para harakwá que podiam fornecer a mim, é a que um karai entenderia. Portanto, presumo, traduziram diretamente harakwá ou haka'ape por essa ideia de "minha área".
} 
ao menor surgimento de um rastro, indicação de um sonho ou mesmo a pura vontade de caçar, como veremos mais abaixo.

Forline (1997), que realizou um estudo sobre a alocação do tempo das várias atividades desempenhadas pelos Awá, demonstra que a caça é, dentre todas as atividades, aquela que os Awá gastam mais tempo em seus dias. Embora cacem com eficiência diversos mamíferos terrestres, são especialistas na captura de mamíferos arborícolas, em particular quatro espécies de primatas: macacoguariba ou "capelão" (warí [Alouatta belzebul]), macaco-cairara (kaibú [Cebus kaapori]), macaco-cuxiú (kitxiú [Chiropotes satanus] e macacoprego (ka'i [Cebus apella]. A técnica, que consiste em uma emboscada aérea dos animais, ainda contemplaria a captura de quatis (kwatxí [Nasua nasua]) e ouriços-caixeiros (kãnú [Coendu prehensilis]), mamíferos também de hábitos arborícolas. A pesca é tradicionalmente uma atividade menos desenvolvida, pois os Awá permaneceram em boa parte de sua história distante dos cursos de grandes rios, não possuíam canoa, ou qualquer técnica mais apurada para a captura de peixes (tal como armadilhas ou represas). Embora os peixes não figurassem no topo das suas preferências alimentares, os rios e igarapés abasteciam as pessoas não só de peixes, mas com a carne de uma espécie de jacaré (jakarê) e poraquês (manaky); além destes, a capininga (jatxaibúa [Kinosternon scorpioides]), um quelônio habitante dos lodos nos igarapés, é muito apreciada.

\section{A floresta no UnIVERSo}

Como na maioria dos grupos Tupi-Guarani, o eixo céu-terra aparece como um dos aspectos fundamentais para o entendimento da forma pela qual os Awá se movimentam no espaço, embora haja exceções como o caso Waiãpi (GALLOIS, 1988). Iwá, ba-ripá e ka'á- "céu", "aldeia" e "floresta” são, respectivamente, os principais centros em torno dos quais a vida gravita, formando pares particulares como "céu-terra", "terra-mata", "mata-céu". Céu e mata são domínios pelos quais os Awá guardam grandes interesses, figurando em boa parte das conversas como tema central, sendo difícil afirmar sobre qual destes domínios as pessoas mais elaboram. A floresta, $k a$ 'á é o local onde sempre viveram, habitat de tudo o que conhecem: animais, mel, remédios; e, apesar de todo perigo que oferece, é o local onde durante sua história recente lhes forneceu a segurança e a distância necessária dos kamará e dos karaí - os "outros indígenas" e os "não indígenas", respectivamente. 
0 patāmar terrestre, chamado $w y$ ' - o local onde vivem os humanos, em que se situa a floresta, $k a$ 'á, é apenas uma pequena parte do cosmos que, além de $w y$, ainda contaria com alguns patamares celestes, os diversos iwá, onde habitam os mortos, e outros seres celestes, tais como os chamados karawá e tapãnas. Sua cosmografia também conta com um mundo subterrâneo, igualmente denominado iwá, onde habitaria uma outra humanidade, sobre a qual os humanos da terra pouco sabem. 0 cosmos seria resultado da separação de um mundo anterior, onde céu, terra e subterra estavam próximos, quase se confundindo. Como em diversas sócio-cosmologias Tupi, os Awá se referem a uma histórica separação das camadas cósmicas, cujo resultado principal foi a "especiação sociológica da terra" (VIVEIROS DE CASTR0, 1986). Para tanto, os Awá narram uma versão curta e um tanto modificada do mito Tupi-Guarani, que versa sobre o dilúvio destruidor de uma primeira humanidade e configurador o mundo atual (também encontrado em outros casos etnográficos como em HUXLEY, 1963, p. 242; LÉVI-STRAUSS, 2004, p. 333-334; VIVEIROS DE CASTR0, 1986, p. 189; para o caso em questão, ver GARCIA, 2011).

0 conjunto de ambientes compostos pelas $\left(1^{\circ}\right)$ terras firmes em que viviam, wytyry, passando às $\left(2^{\circ}\right)$ zonas de várzea e os cursos de rio, ou simplesmente "água", 'ya- todo o complexo de alagados que se forma durante os meses de chuva, resultam em um $\left(3^{\circ}\right)$ conglomerado de áreas de caças identificadas por diferentes topônimos, e composta por uma infinidade de trilhas $(-p \bullet \bullet)$ e algumas clareiras que compõem e atravessam todo o território tradicional. A esse conjunto territorial os Awá denominam haka'a ("minha floresta"), de forma genérica, e, mais especificamente, harakwá ("lugar de"/"meu domínio"). A tradução para haka'á ( $h a, 1^{a} \mathrm{p} . \mathrm{s}+k a$ 'á, "mata"; "nossa mata") é simples e, salvo engano, não sugere muitas interpretações, podendo, inclusive, ser encontrada entre outros povos TupiGuarani, como entre os Parakanã, que definem "território" por ore-ka'á ("nossa mata") (FAUSTO, 2001, p. 104). Harakwá, por sua vez, é uma noção enfatizada pelos Awá denotando não só a mata ( $k a^{\prime}$ á), mas também as relações estabelecidas entre pessoas, animais, plantas, acidentes naturais e todos os elementos que estão relacionados com o território: são espaços onde ações, história e memória coletiva são inscritos. Harakwá é uma noção central na territorialidade/ socialidade Awá, e expressa a relação não só dos humanos, mas também de outros seres com seus "sítios de vida" (floresta, águas, céus, aldeias, dentre outros).

0 conhecimento sobre o território, e, mais particularmente, o conhecimento botânico dos Awá-Guajá é tributário sobremaneira da caça. Cormier ressalta 0 
contraste entre o número de plantas utilizadas pelos humanos (seja para consumo, medicamentos, xamanismo, dentre outros), e o número de plantas conhecidas consumidas pelos animais de caça, mais especificamente os macacos. A autora conclui que "o conhecimento etnobotânico dos Guajá é funcionalmente integrado com o seu modo de produção forrageiro, que se concentra nos macacos enquanto caça (preferencial)" (CORMIER, 2003, p. 50). Em uma amostragem elaborada pela autora contendo 275 espécies e morfoespécies de plantas não cultivadas conhecidas pelos Awá, foi constatado que $84 \%$ destas são espécies conhecidas por serem alimentos dos animais caçados, enquanto apenas 14.91\% representam aquelas que são consumidas pelos seres humanos (CORMIER, 2003, p. 50-51). A autora ainda encontra entre as plantas conhecidas consumidas pelos animais de caça em geral, uma ênfase dos Awá naquelas consumidas pelos macacos. Do universo de plantas consumidas pelos animais de caça e conhecidas pelos humanos, 51.94\% são consumidas pelos macacos, sem dúvida uma das caças preferenciais dos Awá-Guajá que, segundo Cormier, possuem uma predileção especial pelo macaco-guariba (warí [Alouatta belzebul]).

A relação entre "caça" e "território", cujo resultado é o conhecimento sobre o ambiente da floresta, é destacado em outras etnografias. Os Yanomami são um caso interessante. Segundo Albert e Milliken (2009, p. 64):

Os caçadores Yanomami têm um conhecimento excepcional da ecologia do seu habitat, competência de vital importância para seu êxito na caça. 0 conhecimento sobre as plantas das quais suas presas se alimentam, aliado ao conhecimento sobre fenologia e a distribuição desses vegetais, faz, assim, com que os caçadores Yanomami possam prever, com certa segurança, quais os animais propensos a ser encontrados em determinados lugares, e em diferentes estações do ano. Em certos casos as plantas têm propriedades que afetam diretamente os animais que as ingerem, e assim modificam seu comportamento frente aos caçadores. Desse modo, segundo o relato de MatteiMuller (2007), grandes aves são mais fáceis de caçar depois que comem frutos de Guarea guidonia (mokomoko hi) que as enfraquece. Já os cães de caça são impelidos de consumir suas vísceras para não serem envenenados.

Os autores afirmam que tal conhecimento ultrapassa a "simples familiaridade com os hábitos dos animais de caça”, e se revela como "um domínio fundamental do saber etnobotânico dos Yanomami, assim como dos outros povos da floresta tropical." (ALBERT; MILLIKEN, 2009, p. 64). 0 argumento acima é, em muitos aspectos, semelhante ao que acertadamente defende Cormier para 
o conhecimento etnobotânico Awá-Guajá. Caça e território são compreendidos em conjunto, pois trata-se de um povo cujo conhecimento sobre o território é expressado (e, muitas vezes derivado) da atividade caçadora, fruto de uma histórica relação com o espaço, em um ambiente social em que as aldeias eram praticamente inexistentes, e as caminhadas pela floresta bastante frequentes.

\section{A DINÂMICA DO HARAKWÁ}

Harakwá (que, como vimos, pode ser traduzido por "lugar de") é um termo que os Awá costumam traduzir aos karaí (não indígenas) como "minha área”, o que (de forma a simplificar a tradução e o diálogo) faz alusão ao recente processo de demarcação jurídica, principalmente da recente área indígena "Awá". Harakwá, como tantas outras palavras, é composta pelo pronome $b a^{7}$ e a palavra (r)akwá, que pode ser traduzida por "conhecer", "saber". Em outras formas, como ima-rakwá, pode ser traduzido como "lembrar" ou "pensar", a depender do caso. Neste sentido, harakwá é o local (re)conhecido enquanto tal por um grupo (familiar, local, etc.), por onde estas pessoas circulam, e dele sobrevivem, caçando e manejando recursos.

Os harakwá eram "exclusivos" de uma família e/ou grupo local que o conhecia intimamente. As "fronteiras" eram dadas por outros harakwá conhecidos, muitas vezes de germanos ou cognatos próximos, ligados por parentes de parentes, até uma distância na que a genealogia e o território não mais alcançavam ${ }^{9}$. Se existem formas marcadas de herança que regulam e delimitam os diferentes espaços (destinados a cada grupo familiar), as regras de circulação

\footnotetext{
${ }^{6} \mathrm{Na}$ língua Guajá, o pronome "bâ" é traduzido diretamente como um pronome possessivo da $1^{a}$ pessoa do singular (ex."meu"), e utilizado como parte integrante em muitas palavras, inclusive nos termos de parentesco.

${ }^{7} 0$-akwá da língua Guajá encontra cognatos em outras línguas Tupi-Guarani, como o -kuaa do Guarani Mbya, que pode ser traduzido por "saber" ou "aprender" (DOOLEY, 1982, p. 92).

${ }^{8}$ Cormier traduz a idéia de harakwá por "meu conhecimento", ou ainda como "(área) conhecida por germanos do mesmo sexo", afirmando que as "fronteiras" dessas áreas são percebidas pelos Awá e "defendidas com muita intensidade". Mesmo afirmando que muitos desses espaços vitais são herdados em linha agnática, Cormier afirma que o uso dele é feito por germanos de ambos os sexos, e tanto esposas quanto maridos ocupam a área da família de um e outro (CORMIER, 2003, p. 73).

9 Tal como observa Rivière a partir das distintas formas de reciprocidade entre núcleos residenciais em toda a região das Guianas (RIVIÈRE, 1984).
} 
e troca de pessoas entre os harakwá obedecem primordialmente à distância social entre seus ocupantes, e não existem prescrições claras estipulando regras de residência. Além disso, nas últimas décadas, o parentesco e o território foram abalados de tal maneira pelo contato com o Estado brasileiro - e as mudanças advindas deste processo vivenciadas tragicamente, mesmo antes dos anos setenta do século passado quando o contato foi iniciado, que as experiências de fuga interferiram diretamente nas escolhas e destinos das pessoas, seja no campo do parentesco, quanto do território.

Neste contexto, as noções de parentes "próximos" e "distantes" são fundamentais para compreendermos esta ocupação cognática do território. Os próximos e os distantes, harapibiara e harapibianã respectivamente, são classificados também a partir da distância genealógico-espacial. Aqui, todas as pessoas do lado materno e paterno reconhecidas como "consangüíneas" pelo ego são considerados harapibiara, e todos os outros, estejam perto (como, por exemplo, o filho da irmã ZS) ou longe, são harapibianã. Os Awá costumavam classificar os co-residentes de um mesmo harakwá por harapibiara, e a medida que as distâncias aumentavam, os "outros" eram harapibianã, que, neste caso, poderiam ser desde afins casáveis a inimigos em potencial. Após o contato com o Estado brasileiro, a atual situação das aldeias Awá fez com que diferentes grupos de pessoas vivessem proximamente, como não haviam experimentado até então. Hoje em dia, mesmo muito próximas, as pessoas se dividem para as atividades cotidianas, como as caçadas ou a agricultura emergente, a partir dos mesmos conjuntos cognáticos que antes, na floresta, encontravam-se com menos intensidade, e jamais experimentariam uma vida juntos.

Ao traçar uma distinção analítica entre as ideias de rotas (routes) e trilhas (trails), como maneiras de se movimentar no espaço, a partir de alguns exemplos sobre povos caçadores do Ártico, Austrália e Papua Nova Guiné, Ingold (2007, p. 79) nota como em muitos desses casos o "território" é a soma de caminhos e estratégias que movem as pessoas em seus espaços vitais. A mobilidade territorial de diversos povos, sobretudo os chamados "caçadores", são repletas de imagens que ilustram suas relações com o espaço. Por exemplo, entre a população Inuit de Igloolik, ao norte do Canadá, viajar não é somente uma atividade de transição entre um local e outro, mas um "jeito de ser" ("way of being"), pois quando 0 gelo do inverno derrete, e a água cobre todos os caminhos, as pessoas passam a se locomover com seus caiaques; porém, as trilhas feitas durante a neve estão em suas memórias e são por esses mesmo caminhos, embora agora fluviais, que as pessoas 
se locomovem (APORTA, 2004 apud INGOLD, 2007, p. 76). Ou, como ocorre entre os Foi de Papua Nova Guiné, cujas viagens, sempre a pé, não são meramente uma questão de deslocamento de um ponto a outro, uma vez que, em cada uma dessas jornadas, observam-se cuidadosamente a qualidade dos caminhos e os alimentos que podem estar florescendo (frutas, larvas, rastros de animais, etc.), já que esse grupo trabalha seus caminhos, transformando-os em canais condutores de todas as suas atividades (WEINER, 1991 apud INGOLD, 2007, p. 76). Ou ainda, o caso dos Walbiri do deserto australiano, cuja vida de uma pessoa é considerada a soma de seus rastros, traçados (e, portanto, inscritos) no solo ao longo de sua vida (WAGNER, 1986 apud INGOLD, 2007, p. 79).

Entre outro povo Australiano, os Chatwins, as pessoas imaginam suas terras não como uma área que pode ser dividida em blocos (como fazemos, por exemplo, com um mapa), mas como uma rede interconectada de linhas e caminhos, e as palavras que as pessoas utilizam para definir o que é a sua "terra" (country) são as mesmas para "linhas" (no sentido que lhe empresta Ingold, de caminhos e trilhas) (INGOLD, 2007, p. 76). 0 mesmo ocorre com vários povos da Amazônia, sobretudo os que têm na caça a sua atividade central. Como defende Rival para os Huaorani do Equador, cujo "território" não pode ser visto como um espaço demarcado com limites definidos em todos os seus lados, ele é antes uma rede de caminhos utilizada pelas pessoas quando "andam pela floresta" (RIVAL, 2002). 0 padrão de assentamento destes grupos se assemelha, por exemplo, ao dos Parakanã ocidentais antes do contato (FAUSTO, 2001, p. 113), cuja aldeia era o acampamento, sem um modelo de aldeia base com casas permanentes; tudo 0 que eles conheciam eram os tapirís da mata, casas monofamiliares e aldeias sem roças ou praça.

Com o harakwá acontecem processos semelhantes, e tal ideia não se liga a uma porção indefinida (fluida, imprecisa) de floresta; muito pelo contrário, os limites são (ou eram) estabelecidos a partir de variáveis que determinavam a ocupação de certa área por algum grupo de pessoas - seja por casamento, sucessão por morte ou disputas pelo espaço. 0 harakwá é transformado por quem o ocupa, refeito em diversas situações diferentes (a depender da época do ano, da necessidade e da oferta de recursos), ao mesmo tempo em que determina as ações de seus ocupantes. 0 harakwá pode ser visto como "fator limitante", ao mesmo tempo em que os homens, através de suas constantes intervenções, o limitam. Repleto de trilhas, um harakwá é conhecido intimamente; em cada caminhada, o território é varrido, e novas informações produzidas. Todos os indícios são levados 
em conta: galhos partidos, frutos mordidos por animais, áreas com terra pisada e folhas reviradas; cada uma dessas informações é utilizada como base para as caçadas e futuras incursões. Os planos são permanentemente refeitos durante as caminhadas na mata; por isso, uma pescaria se transforma facilmente em uma coleta de pequis (mykya'â), e a caçada a uma paca (kararubú) é abandonada pelas fezes de macacos-pregos ( $k a$ 'i $\left.k a k a^{\prime} a ́\right)$ recém-encontradas ${ }^{10}$, indícios de outra caçada por vir. Ao passarem por lugares aparentemente "selvagens", os caçadores percebem que ali, entre aquelas folhas, dormia uma anta (tapira), que nunca conseguiram matar; ou que as folhas imperceptivelmente remexidas embaixo de uma árvore de tatajuba (taryká) são rastros de uma paca que ainda circula por ali; ou ainda, que a trilha larga que encontram não é propriamente uma "trilha" (hapé), mas o "rastro" (ipópóra) de uma vara de porcos (txahó), um tipo de animal que também sabe abrir caminhos (-pé).

Não tenho como precisar o tamanho de um harakwá, mas tendo em vista as incursões que fiz em diversas dessas áreas, estimo que já possam ter oscilado entre 50 e $80 \mathrm{~km}^{2}$, talvez um pouco mais, a depender do momento histórico que os Awá viviam ${ }^{11}$. Além disso, as últimas três décadas trouxeram mudanças na forma de se organizarem no espaço. Se as novas configurações das aldeias foram alteradas, dando lugar a aglomerados populacionais formados por diferentes grupos, os espaços de circulação desses grupos também foram profundamente afetados.

Nos dias atuais, as aldeias parecem possuir em seu entorno áreas comuns (barakwá), com alguns grupos familiares privilegiando certos espaços mais "exclusivos" para seu uso, em detrimentos de outros. Tais escolhas são determinadas pelo conhecimento pregresso que cada família possui de uma área, além das novas alianças realizadas nos anos recentes, após o contato. Embora diferentes grupos locais vivam um novo padrão de vida aldeã, os harakwá ainda

\footnotetext{
${ }^{10}$ Cormier (2003) discute como o conhecimento botânico dos Awá tem sólida base no conhecimento que possuem dos hábitos dos animais, e eles conhecem um número maior de plantas que servem para o consumo animal do que de uso direto dos humanos. Muitas destas plantas recebem o nome do animal que a utiliza, seja por que ele a consome, seja por que habitam locais onde tais plantas se proliferem (ou ainda outros motivos); portanto, muitas vezes, são bons indícios para se perceber a presença de determinado animal no local.

${ }^{11}$ Gomes observa que as áreas tradicionais dos grupos locais tinham em média $100 \mathrm{~km}^{2}$. Talvez no passado isso possa ter ocorrido; porém, desde o adensamento humano na Pré-Amazônia, nos dias atuais, esse é um número superestimado (GOMES, 1991).
} 
são pensados como áreas "exclusivas", onde, porém, devido à nova realidade, famílias que frequentam determinada área da floresta podem também caçar em áreas de outros grupos familiares, quando se relacionam diretamente entre si. Tal aspecto é discutido por Cormier quando define, nos dias de hoje, os harakwá como áreas comuns de parentes consanguíneos do mesmo sexo (CORMIER, 2003, p. 72 74). É fato que, alguns indivíduos, principalmente os mais velhos, não abrem mão das áreas pelas quais já circulavam antes do contato, como é o caso, por exemplo, de um indivíduo denominado "Kamará"12, que, ao acompanhar o grupo de seu genro em caçadas em outras áreas, age como se estivesse "prestando serviços", tal como nas seguintes situações: (1) encontra-se, após a caçada, com o grupo de seu genro em um local previamente combinado a fim de carregar, junto com os outros, a pesada carga de animais abatidos; (2) ajuda a moquear a caça, ainda na floresta, antes de voltar à aldeia; ou ainda, (3) ajuda os caçadores com o seu domínio de diferentes técnicas de caça. Ao penetrar em outros harakwá, Kamará quase sempre parece um "intruso", ainda que nos dias atuais as comunidades vivam em aldeias comuns. Por isso que, ao caçarem nos harakwá de outros, os homens podem fazer às vezes de um "convidado", um estranho, um parente distante (barapihianã) aproveitando a boa oferta de carne daquela área, colocando os seus serviços em troca.

Chamo atenção para o fato da noção de harakwá não estar limitada ao plano das relações humanas. Se partes da floresta são o harakwá dos humanos, alguns animais, além de outros seres, possuem os seus próprios harakwá. Esse fenômeno foi primeiro observado por Cormier - embora pouco explorado, observando que os Awá situam a terra em que vivem os humanos (wy') como o harakwá do demiurgo Maíra, Mai'irakwá na grafia da autora (CORMIER, 2003, p. 72). No decorrer do meu trabalho de campo, outros harakwá também apareceram como ligados a distintos animais, locais onde os animais "gostam" (maparahỹ) de estar. Assim, os cocais da espinhosa palmeira jú (marajazeiro [Pyrenoglyphis maruja]) é o harakwá de uma determinada vara de porcos, um txahórakwá, pois é este o local que encontram comida e "gostam"; da mesma forma, a copa das árvores é o harakwá dos guaribas (wari)- por isso, warirakwá; os buracos (akwáj) são o harakwá dos tatus (tatúa); e as águas o harakwá do jacaré (jakaré), poraquês (manaki) e capivaras (kapiwá). Os Awá não se

\footnotetext{
${ }^{12}$ Kamará é o termo utilizado para se referir a outros povos indígenas, porém, devido a peculiar onomástica awá-guajá, repleta de apelidos, este indivíduo ganhou dos membros da aldeia o apelido "Kamará", tornando-se este o seu nome usual.
} 
reportam aos harakwá de todos os animais que conhecem, mas apenas daqueles pelos quais se interessam, seja por que os caçam, ou simplesmente gostam, conhecendo seus hábitos ${ }^{13}$.

Tal como ocorre aos humanos, para tais animais, a escolha de um harakwá passa pela combinação de hábitos alimentares, acesso a recursos básicos de subsistência e a qualidade do habitat (segurança, conforto, distância segura de predadores, etc.), e tal combinação de fatores é expressa pela idéia de maparãhỹ, "gostar". Warí maparãhỹ ka'á, "os guaribas gostam da floresta", é dito como se explicassem o fato da floresta ser repleta desses primatas, bem como de macacos cuxiús (kitxiu), macacos-pregos (ka'i) e macacos-cairara (kaibú). A ênfase na ideia de "gostar" explica hábitos, gostos e atitudes - dos humanos e de outros seres - com relação à sua vida, por meio da ideia de maparahỹ, utilizada em diferentes contextos, que variam do parentesco à caça.

A caçada a determinado animal é entendida, pela ótica da presa, como uma invasão ao seu harakwá. Os Awá explicam que os guaribas (warí) enxergam os Awá como karaí caboclos, termo pelo qual os próprios Awá se referem aos karaí (não indígenas), invasores de suas áreas. Devido às formas de caça aos guariba que consiste basicamente em uma emboscada aérea, em que os homens sobem nas árvores onde os animais se escondem e lá travam uma pequena batalha, os caçadores são percebidos pelos guariba tal como os Awá percebem os karaí que, por exemplo, abrem estradas nas áreas dos Awá: "são madeireiros que vieram nos matar", pensam os guaribas.

\section{WATÁ - “ANDAR-CAÇAR”}

Watá é o verbo pelo qual são referidas as caminhadas pelo território (barakwá). Traduzido literalmente por "andar", "caminhar" e "caçar", watá não pode ser compreendido apenas como um movimento pelas trilhas de uma área. Além de watá, ainda temos a forma watábá, cuja tradução é "caminhada" ou "caçada", muito utilizada para se referirem a uma jornada de um dia na mata. Watá é sinônimo de muitas ações que se desenrolam no decorrer de uma jornada (andar, caçar e coletar) permitindo afirmar que, para os Awá, as atividades de "andar" e "caçar" são expressas pelo mesmo verbo, watá, uma vez

\footnotetext{
${ }^{13}$ Os Awá chegam a esboçar que até mesmo os karaí (não indígenas) tiveram suas karaí ka'a, "florestas dos karaí", porém as destruíram, e, hoje em dia, estão interessados em destruir as ka'a dos Awá.
} 
que, inclusive, a forma nominal, pela qual todo caçador é referido é watá ma'á, cuja tradução é "caminhador" (ou "caminhante"), e pode ser glosado como "caçador". Em uma aldeia Awá, ao perguntarmos por alguém que tenha ido à floresta, independentemente do contexto (caça, coleta, pesca, etc.), a resposta mais comum é "watá ka'a PE": "foi andar na floresta". As muitas formas de predar uma caça são referidas de acordo com o animal a ser caçado, não existindo uma forma canônica. Como um paralelo, lembro que para diversos povos do noroeste amazônico e piemonte andino, tais como os Ashuar, Huaorani e Tukano, "caçar" é definido como "soprar", uma vez que a zarabatana é o principal instrumento de caça (DESCOLA, 1998, p. 32).

0 principal objetivo de uma caminhada/caçada (watá) é predar algum animal, de preferência uma carne gorda (-kirá "gordo(a)/ gordura") e saborosa (hẽée, "doce"), e, para tanto, se utilizam do verbo -iká, outro com cognatos em línguas da família Tupi-Guarani14. "Jahó warí iká!", "Vamos matar guaribas!", ou porcos, mutuns, pacas, cotias, ou qualquer outro animal, é uma forma usual para se propor uma caçada. Quase sempre, ir a mata é ir "matar" (-iká) alguma caça previamente rastreada, seja por que é a época de frutos dos quais a presa se alimenta, seja por que se sonhou com ela. As ações envolvidas no watá podem ser, além da caça, a pesca, coleta de mel e frutos, ou, por exemplo, o reconhecimento de uma nova área a ser explorada, dentre outras atividades. "Caçar na floresta" pode ser formulado de qualquer uma destas maneiras; porém, o verbo watá, utilizado em sinonímia a "caçar", aponta para diferentes atividades que envolvem incursões pelo território. É caça e coleta, ao mesmo tempo que pode ser uma desculpa ideal, seja para um encontro romântico, ou para um isolamento voluntário com 0 intuito de se livrar de alguma chateação.

Watá sequer pode ser pensado como uma possibilidade técnico-social exclusiva aos humanos, pois as atividades de andar, explorar o ambiente e obter alimentos é propriedade também dos animais. Watá, como ideia associada a diversos seres, pode ser traduzido como "caminhada e procura (por alimentos)". Assim, por exemplo: (1) os karawara, caçadores que habitam os patamares celestes, descem a terra para "caçar" (watâ), a fim de matarem ( $i k a ̂ a)$ presas de sua predileção; (2) as antas, veados e pacas andam (watá) à noite atrás de frutos para comer; (3) os macacos, que pulam de galho em galho atrás de frutinhas e

\footnotetext{
${ }^{14}$ Ver, por exemplo, o -juká "matar", na língua Mbya (DOOLEY, 1982).
} 
folhas para a alimentação, estão em processo de watát ${ }^{15}$. É comum falarem em português que "o veado foi caçar frutos" (watâ); ou, "as baratas foram caçar migalhas" (watâ); e, assim será com todos os seres, com a lógica da "caça" (como sinônimo de caminhada e procura) sendo desempenhada por boa parte dos habitantes do mundo.

Tal como já apresentei, os territórios (barakwá) são recortados por trilhas, e cada trilha possui a sua história particular. Desta forma, andar (watá) - e não remar ou plantar, além de ser a única maneira de encontrarem alimentos (banimi'ua), é a forma, por excelência, de viver. Watá pyry, "andar junto", e mesmo rikô, que poder ser traduzido por "estar junto"/"estar com alguém", são expressões recorrentes para exprimirem os atos de caça, seja longe, nos acampamentos (kaa ripá, "casas na mata"), ou em breves jornadas de poucas horas. Durante uma caçada, nas caminhadas aos locais pré-determinados, watá será sempre watá-paj, que pode ser traduzido por "andar rápido", ideia que contrasta com watá-me, "andar lentamente" (ou, literalmente, "andar mole"), como se deve fazer em momentos de descanso, descontração, ou mesmo quando retornam de uma caçada. Nesse registro, "andar" é "caçar" e vice-versa, e podemos pensar tal ideia não como passível de duas traduções, mas como uma forma particular de se estar no mundo, um "andar-caçar". Se a atividade de caça é também a produção de alimentos - 0 aprovisionamento (procurement, nos termos de Ingold, 2000 e Bird-David, 1992), ela não existiria sem uma elaborada produção de significados e sentidos sobre a caminhada.

É importante ressaltar que não existam caçadas que uma esposa não possa participar junto com o seu marido ou irmãos, sendo muito comum as meninas recém noivas, ainda morando na casa de seus pais, acompanharem os homens com quem irão se casar. Mesmo a caçada de queixadas, sempre a mais desgastante e perigosa dentre todas - quando os homens são obrigados a se separar, saindo completamente dos caminhos e trilhas usuais, se embrenhando por espinhos e áreas fechadas da mata, tudo isso correndo muito, as mulheres podem se fazer presente em boa parte do processo. Em outras palavras, um casal pode "andar junto" (watá pyry) atrás de caça, e o interesse de uma mulher por caçar é mais do que desejável, uma vez que, como estamos vendo, durante muito tempo esta foi a "única" atividade produtiva na obtenção de comida.

15 "Neither foraging nor production is an adequate description of what hunters and gatherers do. As an alternative, Bird-David suggests procurement" (INGOLD, 2000, p. 58). 
Para os Awá, nada mais "natural” que as esposas se envolvam nas caçadas, e a partilha de interesse de uma mulher por tal atividade quase sempre só tem a acrescentar ao desempenho de seus maridos. Por outro lado, o fato da floresta ser supostamente mais perigosa para uma mulher do que para um homem, parece ser, ao menos aparentemente, algo com que todos concordam, pois os homens por possuírem armas, conseguirem subir em árvores, aguentarem mais peso, dentre outras vantagens técnicas, são mais preparados para enfrentar a mata e, em poucas palavras, a vantagem masculina passa muito mais pelo fato dos homens possuírem armas, e as mulheres não. Ou, como observou Paola Tabet, "Ce n'est pas la chasse qui est interdite aux femmes, ce sont les armes" ("Não é a caça que é interdita às mulheres, mas as armas") (TABET, 1979 apud BRIGHTMAN, 1996, p. 705). Por isso, a divisão do trabalho para a obtenção de alimentos, coincide com a divisão dos meios tecnológicos. Nesse caso, quem domina as armas domina melhor 0 ambiente, e, por isso, a floresta oferece menos risco aos homens do que às mulheres.

Assim, a ideia de "caminhar junto", tal como os Awá enfatizam, prescrevendo não apenas "caminhar junto" com outros companheiros de caça, mas também com a esposa e os filhos, é reveladora do estatuto que os Awá dão às caminhadas-caçadas. A pouca intimidade dos Awá com rios, e as atividades a eles relacionadas, contrasta com o profundo conhecimento histórico que desenvolveram sobre a floresta, ainda densa, que cobre seu território, sobretudo as serras e as montanhas que compõem parte da região pré-amazônica, pela qual transitam há mais de um século. Refúgio que marca a trajetória deste povo que, inseridos em uma região da Amazônia marcada por violência e destruição ambiental, foram forçados a abandonar constantemente suas aldeias, levando uma vida de movimento permanente, recriando a todo momento seus saberes e formas de vida.

\section{ConClusão}

Como vimos acima, para se compreender as muitas relações dos Awá com o território (suas concepções e ações), é necessário compreender como se movimentam no espaço e, sobretudo, caçam. 0 que está em jogo é um constante processo de conhecer e intervir (no ambiente), no qual o movimento "andarcaçar" (watâ) produz o território (harakwá). Etnograficamente, humanos e animais percebem o espaço de acordo com as suas experiências (tal como vem 
sendo discutido por outros autores como VIVEIROS DE CASTRO, 1996 e LIMA, 1996), e as muitas invasões ocorridas atualmente em suas áreas são o fim não só dos seus harakwá, mas dos harakwá de muitos animais. Este é um dos principais problemas relacionados às invasões ilegais e à derrubada de madeiras. Além do desastre ambiental que todos percebemos, as espécies animais, quando não morrem, fogem à procura de novos e distantes harakwá.

Ocorre aos Awá, nos dias atuais, o que parece ser uma constante em diversos contextos amazônicos contemporâneos, onde os territórios demarcados, quando não estão bastante invadidos, estão ameaçados por pressões no entorno das terras, o que traz uma limitação dos períodos de deslocamento e alcance de áreas importantes para a caça e coleta (para outros exemplos relativos à limitação do trekking em povos caçadores coletores ver Rival, 1999, Lee e Daly, 1999). Enquanto que, no passado, os grupos locais, formados por uma ou algumas famílias viviam em aldeias provisórias ou semi-permanentes, refeitas durante os deslocamentos constantes dos grupos, nos dias atuais, após a reunião das pessoas em aldeias permanentes (pensadas pela FUNAI), encontramos conglomerados de ex-grupos locais que foram reunidos no "formato aldeia", devido tanto à proximidade com o posto da FUNAI (dispondo de seus bens e serviços), quanto um maior conforto oferecido pelas novas casas permanentes, sobretudo na época das chuvas. Os pequenos acampamentos, próximos às áreas com grande oferta de caça e frutos, deram lugar a grandes clareiras, com dezenas de casas, onde vivem até 180 pessoas, cada vez mais distantes dos locais de caça, que, no entanto, por serem incapazes de manterem uma vida como horticultores, precisam voltar diariamente ao mesmo interior da floresta onde outrora viviam. Andam para cada vez mais longe, para onde a caça se foi.

\section{REFERÊNCIAS}

ALBERT, Bruce; MILIKEN, William. Uribi A: a terra-floresta Yanomami. São Paulo: ISA-IRD, 2009.

BALÉE, William. Footprints of the forest: Ka'apor ethnobotany - the historical ecology of plant utilization by an amazonian people. New York: Columbia University Press, 1994.

BIRD-DAVID, Nurit. Beyond the original affluentsociety: aculturalist reformulation. Current Anthropology, Chicago, v. 33, n. 1, p. 25-47, 1992. 
BRIGHTMAN, Robert. The sexual division of foraging labor: biology, taboo, and gender politics. Comparative Studies in Society and History, Cambridge, v. 38, n. 4, p. 687-729, 1996.

CORMIER, Loretta A. Kinship with monkeys: the Guajá foragers of eastern Amazonia. New York: Columbia University Press, 2003.

DESCOLA, Philippe. La selva culta: simbolismo y praxis en la ecologia del los Ashuar. Quito: Abya-Yala, 1998.

. As lanças do crepúsculo: relações jívaro na Alta Amazônia. São Paulo: Cosac Naify, 2006.

DOOLEY, Robert A. Vocabulário do Guarani. Brasília: Summer Institute of Linguistics, 1982.

FAUSTO, Carlos. Inimigos fiéis: história, guerra e xamanismo na Amazônia. São Paulo: EDUSP, 2001.

FORLINE, Louis Carlos. The persistence and cultural transpormation of the Guajá indians: foragers of Maranhão State, Brazil. 1997. Thesis (Doctor in Anthropology) - University of Florida, Miami.

GALLOIS, Dominique Tilkin. O movimento na cosmologia Waiãpi: criação, expansão e tranformação do universo. 1988. Tese (Doutorado em Antropologia Social) - Universidade de São Paulo, São Paulo.

GARCIA, UiráF. Karawara: a caça o mundo dos Awá-Guajá. 2011. Tese (Doutorado em Antropologia Social) - Programa de Pós-Graduação em Antropologia Social, Universidade de São Paulo, São Paulo.

GOMES, Mércio Pereira. 0 povo Guajá e as condições reais para sua sobrevivência. In: Povos indígenas no Brasil 1987/88/89/90. In: RICARDO, Carlos Alberto. Povos indígenas no Brasil 1987/88/89/90. São Paulo: Centro Ecumênico de Documentação e Informação - CEDI, 1991. p. 354-369.

HOLMBERG, Allan R. Nomads of the long bow: the Siriono of Eastern Bolivia. New York: The Natural History Press, 1969.

HUXLEY, Francis. Selvagens amáveis: um antropologista entre os índios Urubus do Brasil. Rio de Janeiro: Companhia Editora Nacional, 1963.

INGOLD, Tim. The perception of the environment: essays in livelihood, dwelling and skill. London: Routledge, 2000. Lines: a brief history. London: Routledge, 2007. 
JARA, Fabíola. El camino del kumu: ecología y ritual entre los Akuriyó de Surinam. Quito: Abya-Yala, 1996.

LARAIA, Roque. Tupi: índios do Brasil atual. São Paulo: Universidade de São Paulo, 1986.

LEE, Richard; DALY, Richard. The Cambridge encyclopedia of bunters and gatherers. Cambridge: Cambridge University Press, 1999.

LÉVI-STRAUSS, Claude. O cru e o cozido. São Paulo: Cosac Naify, 2004.

LIMA, Tânia Stolze. 0 dois e seu múltiplo: reflexões sobre o perspectivismo em uma cosmologia tupi. Mana: Estudos de Antropologia Social, Rio de Janeiro, v. 2, n. 2, p. 21-47, out. 1996.

RIVAL, Laura M. Introduction: South America. In: LEE, Richard; DALY, Richard. The Cambridge encyclopedia of hunters and gatherers. Cambridge: Cambridge University Press, 1999. p.77-84.

. Trekking through history: the Huaorani of Amazonian Ecuador. New York: Columbia University Press, 2002.

RIVIÈRE, Peter. Individual and society in Guiana: a comparative study of amerindian social organisation. Cambridge: Cambridge University Press, 1984.

STERMAN, Allyn MacLean. Yuqui: forest nomads in a changing world. Mason, $\mathrm{OH}$ : Thomson Learning, 2001

VIVEIROS DE CASTRO, Eduardo. Araweté: os deuses canibais. Rio de Janeiro: Jorge Zahar, 1986.

. Os pronomes cosmológicos e o perspectivismo ameríndio. Mana: Estudos de Antropologia Social, Rio de Janeiro, v. 2, n. 2, p. 115-144, out. 1996. 